\title{
Unfit for Further Service: Trends in Medical Discharge from the British Army 1861-1998
}

\author{
BP Bergman, SAStJ Miller
}

\begin{abstract}
Military service requires individuals who are free from ill-health and who are physically and mentally robust, and throughout history those who have become unfit for service have been discharged on medical grounds. This paper uses published historical records to examine trends in the rate of discharge for six key conditions for the period 1861-1998 and to draw conclusions. In the late 19th and early 20th centuries, communicable diseases such as tuberculosis and syphilis were a major problem together with illdefined conditions such as "disordered action of the heart". By the mid-20th century, psychiatric and gastrointestinal disorders had become the principal causes of medical discharge, whereas in the late 20th century, the majority of discharges resulted from injuries and musculoskeletal disorders. The pattern of conditions leading to medical discharge from the Army tends to mirror conditions which are prevalent at that time in the civilian population.
\end{abstract}

\section{Introduction}

Military service requires individuals to be free from ill-health and both physically and mentally robust, since the environment in which soldiers may be called upon to serve and the activities which they may undertake are inherently challenging to health(1). The modern Army's rigorous selection procedures, aimed at excluding those suffering from pre-existing disease and injury, help to protect both the individual and the Army from preventable adverse health outcomes.

In earlier times the Army employed only those who were able to give a period of useful military service and paid scant attention to any adverse consequences to their health but, as society has become more averse to risk, the requirement to protect the health of the individual has become paramount. Throughout history, those who have become unfit for further military service, and who were unlikely to be restored to fitness within a reasonable period of time, have been medically discharged (medically retired or invalided). For those who had been conscripted unwillingly into service, medical discharge could be a blessing tempered only by the illhealth or disability which accompanied it, whereas in the modern volunteer Army, medical discharge may represent the loss of a long-term chosen career.

The criteria for discharging a soldier on medical grounds are based on the needs of the Army at any given time, available treatment modalities, societal expectations and legislation. Developments in both prevention and treatment have had a beneficial effect in reducing medical discharge rates for some disorders. This paper explores the changing patterns of medical discharge from the Army by examining a number of key conditions in detail over the period for which comprehensive records exist and draws conclusions from the trends which are demonstrated.

\section{Sources of Data}

Statistical reports on the health of the Army have been published annually since 1859 except for the years 1915 to 1920 and 1937 to 1942 . They were produced as bound volumes until just after World War 2, when a less formal presentation style was adopted. During the 1990s, statistical data were produced in the form of Annual Army Health Tables, published by the Defence Analytical Services Agency (DASA), and since 1998 the information has been promulgated electronically. Inevitably both the nature and format of the data have changed considerably over this period.

Historical data on medical discharges from the Army, for male soldiers only, were obtained from the published reports at 10yearly intervals commencing in 1861 and corresponding with national population census years. This pattern was departed from in two instances: during the Second World War, when 1943 is the nearest year for which data is available, and in 1998 which has been included to provide the most recent comparator. The data was analysed using an $\operatorname{Excel}^{\mathrm{TM}}$ spreadsheet.

As with the format of the published reports, so medical nomenclature has evolved over the period covered by this study. Although the first attempt to classify diseases systematically had been published in the 18th century and the forerunner to the International Classification of Diseases
Ash Vale

Aldershot GU12 5RQ 
(ICD) had been introduced in 1893(2), it was not until 1952(3) that the British Army adopted ICD coding for health statistics. Diagnostic terminology has gone through a period of evolution, with for example the "enthetic diseases" of the 1860s giving way to the more euphemistic "diseases of the generative system" of the 1890 s, the blunt "venereal diseases" of the pre-First World War period and finally the "genito-urinary diseases" of the late 20 th century.

The evolution of modern medical technology has also resulted in a far greater degree of diagnostic precision than was possible in earlier years. The advent of advanced cardiological and gastroenterological diagnostic procedures has rendered redundant such vague terminology as "disordered action of the heart" and "dyspepsia". Accordingly archaic diagnoses disappear from the reports over time, whilst new diagnoses start to appear. In analysing trends over many years, it has therefore been necessary to use best possible interpretation in order to compensate for these constraints.

\section{Psychiatric Disorders}

During the 19th century, "mental disorders" were often reported under "diseases of the nervous system", a category which also included conditions as diverse as meningitis, encephalitis and apoplexy. It is not until 1891 that a reliable estimate of the disorders of psychiatric origin can be made.

The rate of psychiatric discharge continued to rise throughout the first half of the 20 th century, reaching a peak of $44 \%$ of all medical discharges in 1950 before starting to fall. The 1951 Annual Report claims that in that year: ". . . the greatest relative improvement was in mental defectives, perhaps due to an improvement in the selection of recruits .... mainly owing to the smaller number of dullards . . . from the stricter procedure at preliminary examination". However initiatives had been in place since 1942 to try to select out those who were considered to be predisposed to psychiatric disorders(4).

The pattern of reported psychiatric diagnosis has changed with the evolution of psychiatric practice. In the late 19th century, the mental disorders were considered only as a subset of diseases of the nervous system, although one regional report makes specific mention of cases of melancholia and catalepsy. By 1943, the specialty was well advanced and a detailed breakdown of psychiatric reasons for discharge was given, showing that anxiety neurosis predominated, followed by hysteria, accounting for $39 \%$ and $21 \%$ of psychiatric discharges respectively. By the 1990s the small numbers (76 individuals in 1998) resulted in the psychiatric diagnoses once again being collapsed into a single category of "mental disorders" covering ICD-9 Codes 290-319. Figure 1 shows the changing impact of discharge for psychiatric reasons over time.

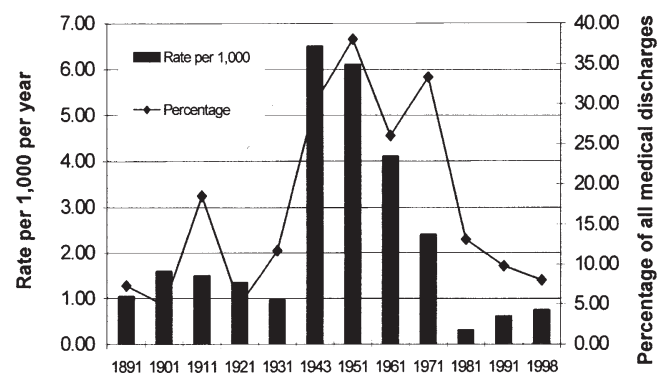

Fig 1. Medical dicharge for psychiatric disorder 1891 - 1998

\section{Injuries}

Although injuries were a common cause of hospital admission in the past, they much more rarely resulted in medical discharge. For example in 1891 in Gibraltar, there was an admission rate of 106.3 per 1,000 men for injury, but only 0.42 medical discharges per 1,000. In 1901, "accidents" constituted $8.6 \%$ of all medical discharges, and this figure was little changed by 1951 when $6.4 \%$ were due to this cause. However by 1998 no less than $31 \%$ of medical discharges resulted from accidental injury. Nonetheless this is due not to the increasing frequency of injury as a cause of discharge, which has changed little from 2.5 per 1,000 in 1901 to 2.8 in 1998 , but to a substantial decrease in the rate of medical discharges due to disease from 26.9 per 1,000 in 1901 down to 5.9 per 1,000 in 1998 as shown in Figure 2.

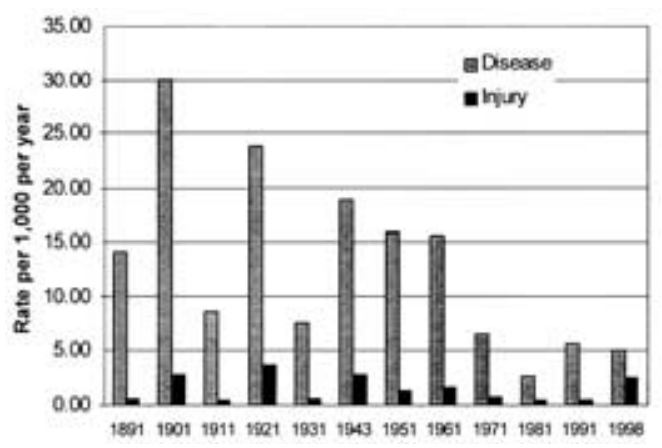

Fig 2. Comparison of medical discharge rates for disease and injury 1891- 1998

The causes of injury have changed with the passage of time. In 1901, there were numerous reports of injury due to such diverse causes as being run over by the wheels of a gun, falling from a horse, crushing by a fall of coal, falling from the ramparts and gunshot wounds. By contrast an analysis of the causes of male medical discharge for injury in the 1990s reveals a predominance of road traffic accidents (including motorcycle accidents) and overuse injuries such as anterior knee pain, ankle sprains or fractures, and low back pain. 
The motor vehicle, which in 1998 was to be responsible for $4.9 \%$ of all medical discharges and $12.6 \%$ of discharges due to injury, was clearly not a factor until the 20th century. However, whereas in 1998 half of all deaths in males under the age of 30 resulted from road traffic accidents(5), by comparison in 1861 half of all accidental deaths in men serving in the United Kingdom were due to drowning, prompting the recommendation that "It seems desirable ... wherever there are facilities for it, the men should receive instruction in swimming". Despite this advice, in 1901 drowning still accounted for some $20 \%$ of deaths due to injury. There is a clear imperative today for action, hopefully more effective, to reduce the burden imposed by road traffic accidents.

A group of conditions which merits separate examination is the disorders of the musculo-skeletal system, classified in later reports as "diseases". Many of these conditions, whilst not clearly originating from an episode of trauma, are nonetheless likely to have arisen from the adverse effects of physical exertion. These conditions, shown in modern reports as "Other disease of knee, joints" and "Musculo-skeletal system, other" demonstrate an increase from 0.7 per 1,000 in 1981 , when they constituted $21.9 \%$ of all medical discharges, to 3.35 per 1,000 in 1991 when they made up $53.3 \%$ of total discharges and $61.8 \%$ of discharges due to "disease". Detailed examination of medical discharge figures for this period showed that there was a sharp increase between 1983 and 1985, coinciding with the introduction of both the Common Military Syllabus for Recruits $(\mathrm{CMS}(\mathrm{R}))$ and the combat high boot(6). In recent years there has been a slight fall to 2.66 per 1,000 serving males or $33.6 \%$ of all discharges in 1998, but these conditions are undoubtedly a major contributor to personnel losses.

Data for earlier years are more difficult to extract but the "musculo-skeletal disorders" of today may be broadly comparable with the group of conditions described as "diseases of the organs of locomotion" which were responsible for medical discharge rates of 2.35 per 1,000 in 1921 and 0.94 per 1,000 in 1931. The explanatory notes of 1931 show that flat foot and hallux valgus had been a major cause of disability and discharge in the 1920 s, but that careful selection of recruits and "more rational periods of physical training with avoidance of long periods of standing on parade by immature recruits" had reduced the number discharged for this reason from 178 in 1923 to 56 in 1931(7). By contrast in the 1990 s anterior knee pain and shin pain syndromes were major contributors to lower limb disability, whilst both hallux valgus and symptomatic flat foot were rare in soldiers.

Stress fracture was a common cause of medical discharge amongst recruits in the 1990s, and various factors including poor diet based on "junk food" and a sedentary former lifestyle have anecdotally been blamed as predisposing factors. However it is of interest to note that in 1932 a medical officer who had observed the occurrence of a large number of fractures amongst the soldiers in his medical charge $(2.2 \%$ of them having sustained such an injury in one year) commented, "One is driven to the conclusion that the feeding and general condition of life of the young children and adolescents of our working-classes is not conducive to the laying down of good material in the long bones."(7) Plus ça change...

\section{Sexually Transmitted Diseases}

Venereal disease was common in the 19th century, accounting for 354 in-patient admissions per 1,000 men in the United Kingdom in 1861, and in view of the lack of any satisfactory treatment, major long-term complications such as secondary or tertiary syphilis and urethral stricture were to be anticipated. In $1891,0.98$ per 1,000 men serving were medically discharged on account of sexually transmitted disease or its complications, accounting for $6.9 \%$ of all medical discharges. By 1897, medical discharges for syphilis alone had reached a peak of 2.7 per 1,000 men annually before dropping rapidly in the early years of the 20 th century to only 0.15 per 1,000 or a total of 34 men in 1911. Even during the Second World War the rate reached only 0.33 per 1,000 , although by then the reporting category of "genito-urinary disorders" also encompassed disorders of the kidneys and bladder unrelated to sexually transmitted infection.

The earliest attempt at introducing national controls on the spread of sexually transmitted infection took the form of the Contagious Diseases Acts, the first of which was passed in 1864. This legislation provided for contact tracing and compulsory medical examination of those suspected of passing on infection. However with no effective treatment available, the Acts were of limited value. Indeed early attempts at preventive measures aimed at reducing morbidity from sexually transmitted infection often had a moral tone, as shown in a letter written by the Rev. P. Bull to the Bishop of Lahore(8):

". . I am amazed at the vast improvement that has come over the moral tone of the Army. Both among Army officers and men it is my opinion that the sin which used to be the rule has now become, in many regiments, the exception, and I consider that the moral 
tone on sexual indulgence is higher in the barrack room ... . this improvement in abstention from fornication is not due, in my opinion, to decrease of virility or to increase of unnatural vice...”

For this, society may indeed be profoundly thankful. The real reason, however, for the substantial fall in medical discharge due to this cause in the first decade of the 20th century had been the introduction of effective treatment. The causative organism of syphilis, Treponema pallidum, had been identified by Schaudin and Hoffman in 1905 and had paved the way for the development of the drug Salvarsan by the German bacteriologist Paul Ehrlich in 1909(9). Earlier treatments, claimed to have been effective, had involved injections of highly toxic mercury compounds and are graphically described in the literature $(10,11)$. The development of the antibiotics during the Second World War finally provided a definitive form of treatment.

Today the sexually transmitted diseases remain a threat to the health of Service personnel, but thanks to effective diagnosis and treatment are no longer a contributor to medical discharge except in respect of AIDS if, as with any other serious illness, the clinical condition deteriorates to the point where continued employment is no longer feasible(12).

\section{Circulatory Disorders}

Perhaps no disease of soldiers has been the subject of more emotion and speculation than disease of the heart. The early lack of understanding of the aetiology of cardiovascular disease is well demonstrated in a report published in 1838 by the then Deputy Inspector-General, Dr Nicholson(13), discussing the prevalence of heart disease in soldiers stationed at the Cape of Good Hope:

"It would be difficult to account in any satisfactory manner why diseases of this nature should affect soldiers here more frequently than at other stations; their habits in all situations being so nearly alike, and in this climate there is nothing peculiar which can be supposed to favour their production. I believe that here and elsewhere we must look on intemperance as among the chief causes of the disease under consideration, by keeping up an excitement of the circulation aggravated by high atmospheric temperature; long continued gastric derangement, induced by the same cause, acting remotely on the heart and ultimately terminating in organic lesion, may also be set down as a probable cause. As rheumatic afflictions, too, are in this climate very prevalent and marked by such peculiar severity, may it not be supposed, that many of the complaints of the heart have their origin in that disease by translation of the morbid action."

Dr Nicholson's last hypothesis was perhaps more accurate than he realised. Of the "invalids from the Cape finally discharged the Service" in 1861 , over $24 \%$ were reported to have been suffering from disease of the heart.

Although many of the reports omit diagnostic detail, there are references as early as 1861 to hypertrophy of the heart, aortic disease and inflammation of the heart and pericardium. The 1871 report gives additional detail, and notes that the most frequent cardiovascular causes of invaliding were valve disease and palpitations, whilst death of cardiovascular origin was most commonly attributed to valve disease of the heart and aortic aneurysm. We may today speculate that rheumatic heart disease and syphilis were important aetiological factors.

By the First World War, disorders of the heart were the third commonest cause of invaliding after wounds and chest diseases(14), and the cost in military manpower was high. There was growing interest in the impact of heart disease on military personnel, and some fifty years earlier, during the American Civil War, Da Costa had described a syndrome of "irritable heart", characterised by shortness of breath, palpitations, and sharp or burning chest pain, particularly on exertion(15), together with other vague and variable symptoms such as tiredness, headache, diarrhoea, dizziness, and disturbed sleep. However few patients had been shown to have conclusive evidence of organic disease of the heart, and other aetiologies such as infection or even a disorder of psychological origin were considered likely.

The concept of "soldier's heart" persisted however, and the diversity of diagnostic labels such as Da Costa's syndrome, effort syndrome, disordered action of the heart and neurocirculatory asthenia betrays the uncertainty surrounding this condition. In 1915, Sir Alfred Keogh, Director General of the Army Medical Services, tasked Dr James Mackenzie, an eminent cardiologist, to investigate the problem and after examining the first 300 cases he reported that over $90 \%$ in fact showed no evidence of cardiac disease but were "part of the general condition of weakness affecting chiefly the vaso-motor system and the brain" $(4,16)$. There is a notable similarity to the condition diagnosed as "debility", which had been responsible for up to $10 \%$ of all discharges in the latter years of the 19th century. In 1881 a medical officer in Hong Kong had observed that these cases of debility were "men without any positive disease, simply unfit for duty and not gaining weight or strength in hospital, where many of them remained for long 
periods"(17). As the diagnosis of heart disease gained ground, so cases of "debility" decreased and by 1911 only 17 out of 1,868 , or $0.9 \%$ of all discharges were for this reason, whilst there were 266 invalidings, or over $14 \%$ of the total, for diseases of the heart and circulation of which 30 were for "disordered action of the heart".

That this condition was labelled a "disorder of the heart" was believed to contribute to the anxiety suffered by patients and the consequent poor prognosis for return to duty and, gradually, allegedly less emotive terms such as effort syndrome, neurasthenia and neurocirculatory asthenia came into use. A long-term postal follow up was conducted on soldiers discharged from service with a diagnosis of effort syndrome and after 5 years less than $1 \%$ had developed overt cardiac disease(18).

By the Second World War, diseases of the heart no longer merited a separate reporting category in the medical discharge report, being swept up in the "All Other Diseases" category. This produced an unavoidable gap in the data shown in Figure 3. In 1991 there were 6 medical discharges for this group of conditions falling to only one in 1998, the modern diagnoses including angina and cardiomyopathy.

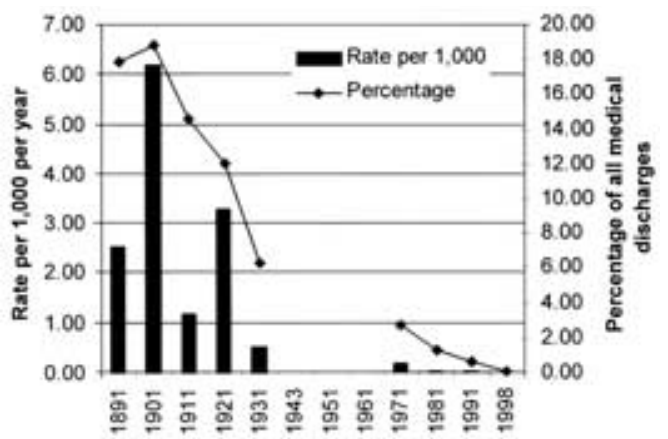

Fig 3. Medical discharge for cardiovascular disorder 1891 1998 less missing data.

\section{Tuberculosis}

Tuberculosis had become common in England during the early part of the 19th century as the industrial revolution drove millions of country-dwellers into poverty and overcrowding in the towns. It was from this urban background that the majority of soldiers were recruited, and the high incidence of tuberculosis in the Army was an inevitable consequence. Although the infectious nature of the disease was already known, it was not until 1882 that Robert Koch demonstrated the tubercle bacillus, and it was to be many years before effective antibacterial treatment became available. In 1861, tuberculosis was responsible for 1,483 admissions to hospital amongst the 81,500 troops serving in the United Kingdom, giving a rate of 18.2 per 1,000 . There were 283 deaths $(3.5$ per 1,000$)$ and 736 medical discharges $(9.0$ per 1,000$)(13)$.
By the late 19th century, the urban sanitary reforms initiated by Edwin Chadwick, supported by the early Public Health Acts and related legislation, were beginning to make an impact on overcrowding and insanitary conditions in Britain's towns, and the incidence of tuberculosis and other communicable diseases had begun to fall. Improvements to conditions in barracks had been implemented in parallel with this, spearheaded by the work of Edmund Parkes, the first Professor of Military Hygiene, and Florence Nightingale. However by 1891 tuberculosis was still responsible for the medical discharge of around 3 per 1,000 of all British soldiers, making it the commonest single cause of discharge due to disease and accounting for some $17 \%$ of all medical discharges. By early in the 20th century the rate had dropped to around 1.5 per 1,000 where it remained, albeit with some year-on-year fluctuation, until the late 1950s and early 1960s when the advent of mass miniature chest radiography, BCG vaccination and effective treatment for the disease led to a substantial decline in both civilian and military cases.

With no effective antibacterial therapy available, treatment for tuberculosis had at first followed the general principles of "rest and fresh air". Indeed the belief in the therapeutic benefit of fresh air was taken to extremes with the sanatorium concept which led to the exposure of patients to the elements in all weathers. In the early part of the 20th century, the practice of artificially collapsing a lung (pneumothorax treatment) by deliberately instilling air into the pleural cavity became popular in the treatment of tuberculosis. However it was not until the 1940s and 1950s that effective therapy in the form of the drugs isoniazid and streptomycin became available and the graph at Figure 4 shows that there was little change in the rate of medical discharge for tuberculosis until the use of these drugs became established. From then on the rate declined steadily, and the last medical discharge of a British soldier for this reason was in 1990.

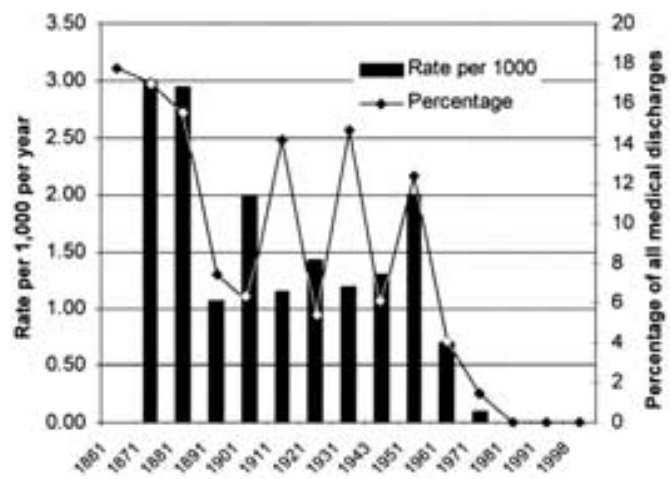

Fig 4. Medical discharge for tuberculosis 1861 - 1998. 


\section{Digestive Disorders / Peptic Ulceration}

During the early reporting years, all "diseases of the digestive system" were aggregated for the purposes of military statistical reporting, but detailed narratives from individual overseas stations show that the conditions most likely to give rise to invaliding under this heading were hepatic disorders and dysentery. In general, discharge for disease of the digestive system appears to have been relatively uncommon in Europe but was a major problem in South Asia and the Far East. For example in Ceylon in 1871, the digestive disorders were responsible for $23.3 \%$ of medical discharges and constituted the largest single cause amongst European troops, hepatitis and dysentery being the most prevalent diagnoses.

Peptic ulceration does not appear to have warranted separate reporting until the early years of the 20th century. There is indeed little to suggest that peptic ulceration was a major problem either in the Army or in civilian life at that time, and a paper reviewing the history of peptic ulceration in the 150 years to 1940 commented on the rarity of the condition in young men prior to the early 20th century(19). Occasional cases of "dyspepsia" were described, and in 1861 two soldiers out of a force of nearly 3,000 were invalided from China back to England for change of climate suffering from dyspepsia, but neither was finally discharged the Service. A comprehensive discussion of peptic ulceration was however included in the 1931 report(7). During the year a total of 110 cases of gastric ulcer and 121 cases of duodenal ulcer had been diagnosed, giving an incidence of 0.61 and 0.66 per 1,000 respectively. The majority were treated medically as surgery carried a high mortality $(12.5 \%$ for gastric ulcer and $14.2 \%$ for duodenal ulcer). Most appear to have made a good recovery; 5 duodenal ulcer patients were medically discharged having undergone surgery, whilst 18 of those treated medically required to be discharged.

The Second World War saw a massive increase in cases of peptic ulceration, and by $1943,13.7 \%$ of medical discharges were for this reason. Many applications for war pension on this account were received, citing the stress of war service as a causal factor, and it has been postulated that many of the cases of chronic dyspepsia and suspected duodenal ulcer may have had an underlying psychological basis, although in a large series of patients suffering from dyspepsia investigated in a UK military hospital(20), $88.6 \%$ had a firm diagnosis of either peptic ulceration or gastritis. Amongst the remainder, psychological disorders were considered to be relatively unimportant and malingering rare, although another report(21) found that $18 \%$ of dyspeptics were suffering from "neurotic dyspepsia". Most patients had a very long history of symptoms, predating enlistment in all but $3.7 \%$ of the duodenal ulcer patients and also, perhaps surprisingly, in the majority of the "neurotic dyspeptics". This finding emphasised the importance of rejection of known cases at the recruitment medical examination. In the first series above, all but one of the patients in whom peptic ulceration had been confirmed were medically discharged, whilst the majority of the gastritis sufferers were able to continue to serve. An editorial noted the incompatibility between chronic dyspepsia and military life(22).

"When men suffer from peptic ulcer in civil life they are enabled to carry on by readjustments of diet and by occasional periods off work, which in cases of declared ulcer average about a month every year. Such forms of adaptation are rarely compatible with combatant service, and the presence of an ulcer therefore means the rejection or discharge of a man from the fighting Services unless he is possessed of very special experience or gifts to outweigh his disability."

After the end of the Second World War, the medical discharge rate for gastrointestinal disorders dropped from a rate of 2.4 per 1,000 in 1943 to 1.3 per 1,000 in 1951 , probably reflecting the greater flexibility in accommodating the needs of ulcer patients which had become possible after the end of global hostilities. This rate was little changed by 1961 as shown in Figure 5, but over the next two decades there was a dramatic fall in the rate of medical discharges for peptic ulceration as the development of new drugs, initially carbenoxolone in the late 1960s followed by the $\mathrm{H} 2$ antagonists and later, treatment for Helicobacter pylori meant that for the first time, effective non-surgical treatment could be offered to ulcer patients. In 1998 it was necessary to medically discharge just one soldier as a result of peptic ulceration.

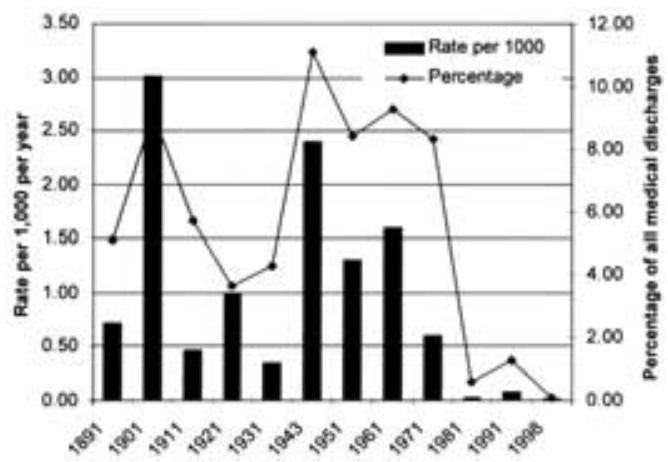

Fig 5. Medical discharge for gastro-intestinal disorder $\mathcal{E}$ peptic ulcer 1891 - 1998

\section{Discussion}

Rates of medical discharge have in general 


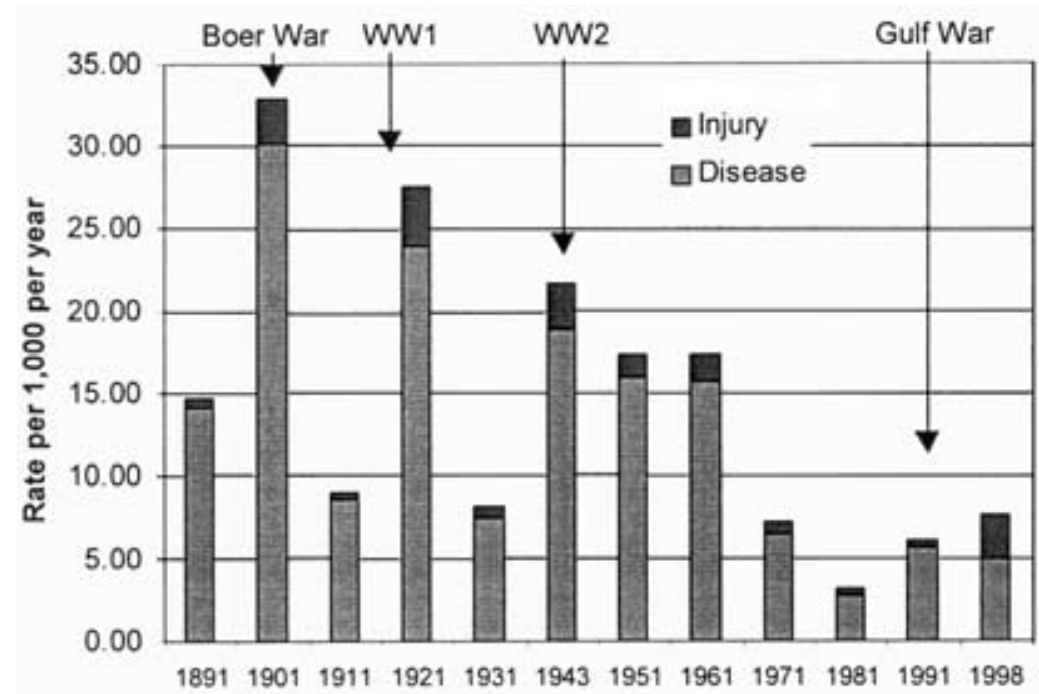

Fig 6. Medical discharge for disease and injury - the influence of armed conflict.

shown a correlation with the intensity of warfighting, with higher rates during the period of the Boer War, immediately after the First World War (figures for the years of the conflict itself not being available) and the Second World War as shown in Figure 6. Perhaps contrary to expectations, the majority of these wartime discharges have not been for combat injury but for disease, confirming the oft-repeated observation that disease and non-battle injury are a greater threat to the health of deployed troops than the enemy. The Gulf War however produced a much smaller rise in medical discharges, and it is only in the last decade that the ratio of medical discharge for disease to injury has fallen from an average level of 15:1 in the century from 1891 to 1991 down to the present ratio of 1.7:1 in 1998 .

Medical discharge data demand cautious interpretation however in order to avoid unwarranted conclusions being drawn. The following extract(13) dating from 1861 illustrates a potential pitfall:

"The invaliding in all the arms .. . has been higher than in 1860, and this may, perhaps, account for the lower rate of mortality. It must not, however, be concluded that the higher ratio of invaliding necessarily implies a greater amount of inefficiency in the different arms of the Service. The strength of the Army having been raised above the authorised establishment it became necessary to reduce $i$. For this purpose recruiting was for a time suspended, and the opportunity was taken to discharge a number of the least efficient men who, although under ordinary circumstances they would have continued to serve, were for this reason included among the invalids."

The six conditions which have been examined all demonstrate different medical discharge patterns. The psychiatric disorders show a rise during the early part of the 20th century reaching a peak around the period of the Second World War, mirroring the rise of psychiatry as a specialty in its own right and the development of innovative (and by modern standards often bizarre) treatments such as insulin coma therapy and the early psychotropic drugs. In the last three decades there has been a substantial fall in medical discharges for psychiatric reasons despite a popular perception that stressrelated disorders are more common. This may be a tribute to early recognition and to more effective management both in primary care and in the workplace, or may reflect the fact that those who are discomfited by stress seek discharge through administrative rather than medical channels.

The rate of medical discharge for injury has remained fairly constant over the last hundred years but the causes have changed, with major trauma featuring less prominently whilst overuse injuries such as stress fractures have become more common, especially in recruits. This mirrors technological developments in the investigation of these conditions such as Xray scintigraphy as well as the rise in the recognition of the problem of occupational overuse injury such as work-related upper limb disorder ("repetitive strain injury") in the civilian population.

The rate of medical discharge for sexually transmitted disease, which was at a high level during the 19th century, dropped rapidly in the early years of the 20th century as the first effective treatment for the conditions became available. As treatment improved with the advent of the antibiotic era, so this group of disorders no longer featured as a cause of medical discharge.

Although medical discharge for cardiovascular disease was common during the late 19th century, most cases had an organic basis in either rheumatic heart disease, syphilitic disease of the aorta or cardiomyopathy. Many new cases of apparent cardiovascular disease of obscure origin presented during the First World War, leading to a huge rise in the rate of medical discharges for this cause, which then fell rapidly during the 1920 s. Although detailed data from the period 1943-1961 is buried in the "all other diseases" category and is thus not readily apparent, the trend in medical discharge for cardiovascular disease appears to have continued to decline smoothly to the present very low level.

Tuberculosis was responsible for many hospital admissions, deaths and medical discharges in Service personnel in the mid19 th century. Rates declined slowly but steadily with improvements in living standards, closely mirroring the civilian population, throughout the latter half of the nineteenth century and early 20 th century, 
finally declining sharply in the 1950 s and 1960 s with the introduction of modern methods of prevention, detection and management before disappearing completely as a cause of medical discharge in British soldiers in 1990.

In the 19th century, peptic ulceration appears to have been rare amongst soldiers as indeed it was amongst young males in the civilian population. There was an unexplained increase in both in the early years of the 20th century, reaching a peak during the Second World War when it was second only to psychiatric disorder as a cause of medical discharge. The rate declined slightly after the end of the Second World War, but then dropped dramatically during the 1970s as new and effective medication came into widespread use, turning a condition which had previously been incompatible with military service into one which could be managed, and in many cases cured, by the unit medical officer.

\section{Conclusion}

The dominant conditions leading to medical discharge have tended to reflect those which are contemporaneously prevalent in the wider civilian community. In the late 19th century, cardiovascular and tubercular diseases predominated, whilst by the Second World War, psychiatric disorders and peptic ulceration were the principal medical causes of discharge. By the close of the 20th century, musculoskeletal disorders and injuries were responsible for $70 \%$ of medical discharges in male soldiers, mirroring the importance of these conditions in the civilian workforce(23). The proportion due to psychiatric disorder had dropped to only $9 \%$, whilst tuberculosis, peptic ulceration and cardiovascular disease had become negligible.

In recent years there has been a small rise in the overall rate of medical discharge, and this is likely to be a reflection of the increasing requirement for all personnel to be fit enough to deploy operationally. It is also more difficult to employ those who are medically unfit as many of those posts which were less demanding and hence more suitable for those who were medically downgraded have been civilianised or even disestablished. Perhaps given the present high level of operational commitment, it is gratifying that the medical discharge rate is still one of the lowest in over a hundred years. This achievement is a tribute to the effectiveness of selection procedures, modern medical treatment and effective preventive measures. The problems which remain a particular challenge are those for which neither predictive parameters nor effective treatments yet exist.

\section{References}

1. JSP 346 Chap 4A (Surgeon General's Policy Letter 25/98).

2. International Classification of Diseases 1975 Vol 1; Introduction.

3. Annual Army Health Report for 1951 .

4. Jones E. The Psychological Impact of Modern Warfare. HQ AG (HS) Army. ATRA 2a/6007.

5. Army Health Indicators 1998. DASA.

6. Jefferson TO. An investigation of medical discharges from the British Army 1979-1986. J R Army Med Corps 1989; 135: 115-123.

7. Annual Army Health Report for 1931 .

8. Report on the Health of the Army for 1911.

9. Encyclopaedia Britannica - www.britannica.com.

10. Lambkin FJ. On the hypodermic administration of mercury in the treatment of syphilis. Army Medical Department Report for the Year 1891. Appx IV, 387-394.

11. Love RL. Report on the treatment of syphilis by hypodermic injection of mercury. Army Medical Department Report for the Year 1894. Appx III 325-331.

12. Surgeon General's Policy Letter 20/97 HIV/AIDS in the Armed Forces - Guidance for Medical Officers.

13. Army Medical Department Statistical, Sanitary and Medical Reports for the Year 1861 (HMSO 1863).

14. Report of the Ministry of Pensions 1919

15. Hyams KC, Wignall FS \& Roswell R. War Syndromes and Their Evaluation: From the U.S. Civil War to the Persian GulfWar, Ann Intern Med 1996;125:398-405.

16. Wooley CF. From irritable heart to mitral valve prolapse: World War One, the British experience and James Mackenzie, Am f Cardiol 1986; 57: 463466.

17. Army Medical Department Report for 1881 .

18. Grant RT. Observations on the after-histories of men suffering from the effort syndrome. Heart 1925;12:121-42.

19. Jennings D. Perforated peptic ulcer. Changes in age-incidence and sex-incidence in the last 150 years. Lancet 1940; 1: 444-447.

20. Gibson Graham J. \& Olav Kerr JD. Digestive disorders in the Forces. Brit Med f 1941; 1: 473-6.

21. Hinds Howell CA. A comparison of dyspepsia in the Army for 1940 and 1941. Brit Med F 1942; 1: 692-3.

22. Editorial. Dyspepsia and cardiovascular neurosis in wartime. Brit Med f 1941; 1: 858-9.

23. Saving Lives: Our Healthier Nation. Government White Paper 1999. 